\title{
Atualidade mundial e desafios brasileiros
}

\author{
FÁBIO WANDERELY REIS
}

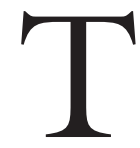

EMPOS ATRÁs, os teóricos do processo de desenvolvimento do Estadonação moderno falavam de três problemas articulados que seria necessário enfrentar e resolver: o problema da identidade, o da autoridade e o da igualdade. O problema da identidade, que se refere à dimensão propriamente "nacional" do trinômio "Estado-nação-moderno", tem a ver com os aspectos de natureza sociopsicológica ou cultural por meio dos quais a definição da identidade pessoal dos indivíduos vem a ser condicionada em medida importante pela inserção na coletividade nacional, que pode, assim, esperar contar com a lealdade de cada qual. O problema da autoridade diz respeito à edificação da aparelhagem administrativa e simbólica do Estado, tornando-o capaz de presença e de ação efetivas junto à coletividade. Já o problema da igualdade, que representaria a face mais especificamente "moderna" da questão geral, refere-se ao desafio da plena incorporação político-social da população, em particular dos estratos populares, envolvendo a acomodação "constitucional" (em sentido sociologicamente denso da expressão, que não deixa de incluir aspectos legais) do convívio entre as classes sociais.

Esse último aspecto se desdobra no tema delicado das relações entre democracia e capitalismo no processo que se dá em cada país. A grande questão há muito situada por aquilo que os teóricos mencionados designam como o problema da igualdade era a de se a incorporação popular poderia ocorrer de forma conseqüente sem que a mobilização produzida pelo capitalismo junto às estruturas sociais tradicionais desaguasse em disposições revolucionárias capazes de ameaçar a sobrevivência do próprio capitalismo. As alternativas históricas de solução estável e bem-sucedida do problema assim posto pareciam, até há pouco, compreender dois tipos de experiência: a dos países de capitalismo avançado, em que o próprio amadurecimento do capitalismo teria vindo viabilizar (em formas variadas de organização, mas mais cabalmente realizadas num modelo assumidamente social-democrático) os mecanismos institucionais de democracia política e de incorporação social, em contraste com a suposição marxista do agravamento das contradições e da eventual ruptura revolucionária; e a dos países 
que passaram por revoluções socialistas, com a acomodação buscando-se em termos da supressão dos fundamentos capitalistas da divisão da sociedade em classes sociais.

O colapso do socialismo, com a feição politicamente autoritária de que as experiências socialistas se revestiram, tem uma primeira conseqüência em evidenciar que não cabe contar com estabilidade real sem democracia, ainda que a repressão possa garantir a longa duração da forma autoritária de organização. A queda do socialismo redunda, além disso, em sugerir que historicamente a única solução estável do problema constitucional consistiria na combinação de prosperidade e democracia que se tornaria possível com o capitalismo avançado. Associada aos efeitos diretos da dinâmica globalizadora pelo mundo afora, ela permite um ethos dominante que não só tem festejado o "fim da história" e o triunfo do capitalismo, mas tem também apregoado um receituário liberal em que se minimiza o papel do Estado e se coloca em xeque o próprio modelo social-democrático.

Contudo, há aqui matizes importantes a recuperar. A forma assumida pela solução dada ao problema da autoridade no mundo da social-democracia, ou seja, o Estado keynesiano de bem-estar, combinava, nos termos utilizados há tempos por David Lockwood, a atenção para problemas de "integração sistêmica" e de "integração social". A integração sistêmica se refere à dinâmica econômica e mercantil em si mesma, com a causalidade automática e cega que a caracteriza no nível agregado e os resultados negativos eventualmente produzidos para a coletividade. Ora, as crises recentes da economia mundial e a incerteza introduzida acarretam revisões importantes nas expectativas otimistas e nas restrições quanto à atuação econômica do Estado próprias do ethos mencionado. Quanto à integração social, que diz respeito ao conflito ou coesão entre grupos e classes e remete ao problema da igualdade e de sua acomodação institucional ou constitucional, o pós-socialismo é o momento em que a dinâmica da globalização passa a mostrar com nitidez a sua face socialmente perversa. Assim, com a crise do keynesianismo e do Estado de bem-estar, o desemprego, a informalização e precarização do trabalho e a desigualdade crescente (num processo que alguns têm designado como a "brasilização" do capitalismo avançado), temos indícios importantes de que ameaça reabrir-se o problema constitucional até nos países capitalistas de maior tradição de estabilidade democrática, embora essa ameaça se dê em condições nas quais a lógica mesma dos mecanismos em jogo debilita os atores que protagonizavam o compromisso político e social anterior (certas organizações sociopolíticas e o próprio Estado) e torna precárias as perspectivas imediatas de reação conseqüente, por parte deles, às novas condições. 
Seja como for, o mundo que a dinâmica globalizadora atual coloca diante dos nossos olhos realiza peculiar disjunção entre os problemas de identidade, autoridade e igualdade de que partimos. De um lado, o Estado nacional continua a prover o foco decisivo quanto a questões de identidade. Não obstante a existência de irredentismos étnicos (que, contudo, visam justamente à afirmação em termos de organização estatal autônoma), a referência aos elementos sociopsicológicos e culturais da nacionalidade segue sendo o principal condicionante do sentido pessoal de identidade, e não há, no plano transnacional, nada que equivalha ao sentimento de inserção numa comunidade de maneira comparável à que se têm no plano nacional. De outro lado, porém, os termos em que se colocam os problemas de autoridade e igualdade são dramaticamente afetados pela globalização. Com o renovado vigor dos mecanismos de mercado, que passam a operar em escala transnacional e virtualmente planetária, não só os Estados nacionais vêem solapado seu poder de administração econômica e intervenção social, mas também a resposta social-democrática ao problema da igualdade tende a surgir como arcaísmo oneroso, e a concepção solidarista de uma cidadania enriquecida pelo desfrute de direitos sociais, ao lado dos direitos civis e políticos, se vê substituída pelo convite a que cada qual se avenha como possa com as asperezas do mercado.

Durante a maior parte do século que agora finda, até que se dessem a intensificação dos mecanismos ligados à globalização e os surpreendentes eventos que resultaram na derrocada do socialismo, as coisas pareciam claras no que se refere ao Brasil. Enfrentávamos aqui o mesmo problema constitucional com que se defrontaram classicamente os Estados nacionais na época moderna. Nosso caso, porém, como o de muitos outros países da periferia do capitalismo mundial, seria o do problema constitucional $n \tilde{a} o$ resolvido, ou resolvido insatisfatoriamente. Num jogo em que com freqüência se pretendeu utilizar certa exacerbação nacionalista da identificação com o país e os instrumentos materiais e simbólicos da autoridade estatal, tivemos a presença continuada da ameaça revolucionária (subjetivamente sentida como tal, quaisquer que fossem os erros de avaliação das "condições objetivas") pairando sobre as turbulências do dia-a-dia e ajudando a conformar o quadro de instabilidade pretoriana, o qual se via marcado pela oscilação entre o autoritarismo aberto, sob controle militar, e tentativas de construção institucional da democracia.

Do ponto de vista do desiderato de implantação efetiva da democracia no país, o colapso do socialismo mundial tem claramente o efeito de neutralizar o papel da ameaça da revolução socialista no jogo político, ao eliminar o eventual respaldo internacional para iniciativas que pretendes- 
sem orientar-se nessa direção e ao esvaziar em grande medida a idéia mesma do socialismo como opção atraente e eventualmente viável. A grande questão é a do significado a atribuir à situação nova para as perspectivas da democracia e de estabilidade institucional: a remoção da ameaça revolucionária, nos termos em que esteve presente na vida política brasileira durante vários decênios, permitirá inferir que a democracia se acha garantida?

Ora, se cabe falar de riscos de reabertura do problema constitucional até nos países de capitalismo avançado e tradição democrática, é bem claro que a presunção otimista dificilmente se justificaria em nosso caso. Afinal, as conseqüências perversas da inserção na dinâmica da globalização tendem a surgir aqui como algo que se superpõe aos fatores tradicionais de desigualdade herdados de nossa longa experiência escravista. Somada à fragilidade institucional que há muito se manifesta nas vicissitudes pretorianas de nossa história republicana, essa circunstância certamente recomenda sobriedade nas apostas com relação ao futuro visível. Será adequado, porém, continuar a falar de "pretorianismo" a propósito das condições que provavelmente prevalecerão, tendo em vista a alusão que a expressão traz ao protagonismo normalmente exercido pelas Forças Armadas em circunstâncias de fragilidade institucional?

O debate político brasileiro em seguida ao fim do regime de 1964 tem privilegiado o tema da "governabilidade". Esse debate se cerca de impropriedades e confusões, a começar por impropriedades semânticas em que a expressão é tomada para indicar uma característica da aparelhagem do Estado (sua eficiência ou capacidade governativa, identificada, no limite, ao mero apoio prestado ao governo no Congresso), omitindo-se o fato de que o atributo de ser mais ou menos governável é um atributo daquilo que é governado, ou seja, da sociedade. A confusão semântica se liga a um postulado substantivo, de acordo com o qual o problema da democracia se acha resolvido. Como o discurso e as ações do governo Fernando Henrique Cardoso deixam claro, o problema a ser enfrentado seria sobretudo o de um aggiornamento do país e do Estado em termos de eficiência e competitividade internacional, de que a implantação da "governabilidade" seria um requisito.

Mas o desiderato da "governabilidade", entendida a expressão em termos de eficiência ou capacidade governativa, não envolve senão o problema "técnico", e de certa forma banal, de manejar adequadamente os meios disponíveis para a realização de fins tomados como dados. Do ponto de vista da democracia, que supõe fins múltiplos de numerosos atores e de compatibilização problemática, a capacidade governativa só interessa na medida em que se ligue com o desafio de criar governabilidade no sentido próprio: o de criar a sociedade que seja governável por boas razões, vale 
dizer, aquela em que os diferentes interesses e correntes de opinião reconheçam no Estado, em grau significativo, o agente autêntico de todos. Nesse plano estamos diante de problemas substantivos e propriamente políticos, que podem ser postos em foco pela consideração de formas diversas de ingovernabilidade em que a questão da igualdade e sua articulação com o aparelho do Estado é central.

Uma delas, que remete, na verdade, ao contexto por referência ao qual o tema da governabilidade foi introduzido nas discussões contemporâneas por Samuel Huntington e outros, é a que se poderia designar como "ingovernabilidade de sobrecarga". Ocorrendo num quadro de crise fiscal do Estado e de demandas crescentes a ele dirigidas, o aspecto a destacar é o de que se trata aqui de uma condição em que se destempera (o "destempero democrático", na expressão de Huntington) o modelo social-democrático de um Estado aberto e sensível à multiplicidade dos interesses. Por esse aspecto, a ingovernabilidade de sobrecarga contrasta fortemente com a segunda forma que cabe apontar, a "ingovernabilidade pretoriana", a qual corresponde ao problema constitucional não resolvido que acima mencionamos e envolve o confronto direto dos interesses diversos num contexto de fragilidade das instituições políticas e de precária capacidade de processamento institucional desse confronto, com a conseqüente tendência ao protagonismo dos militares. Se essa segunda forma nos é familiar, as novas condições mundiais, associadas à exasperação de certos traços que há muito acompanham nossas deficiências sociais, nos expõem com força a uma outra, que se poderia designar como "ingovernabilidade hobbesiana”. Trata-se, neste caso, da deterioração difusa do tecido social, da criminalidade e da violência urbana crescentes, do surgimento de espaços onde a autoridade estatal não tem condições de se fazer valer de modo efetivo - e, assim, do comprometimento da capacidade de ação do Estado no plano da própria manutenção da ordem pública e da segurança coletiva. Na verdade, seria possível dizer que esse comprometimento faz emergir o problema constitucional em sentido mais comezinho e básico, transformando-o no problema, de que se ocupou Hobbes, da constituição ou preservação da autoridade capaz de garantir o anseio fundamental por segurança e ordem. Um aspecto especial a merecer menção é o do papel desempenhado, no quadro de deterioração hobbesiana, pela economia da droga, que, penetrando profundamente alguns países latino-americanos vizinhos, certamente afeta também de maneira crescente o Brasil das chacinas como fenômeno corriqueiro do dia-a-dia.

A indagação principal que emerge quanto à avaliação de nossos prospectos democráticos é talvez a das relações a se estabelecerem entre essas 
diferentes formas de ingovernabilidade. Assim, mesmo com a precariedade do welfare state brasileiro, é provavelmente adequado falar de um problema de sobrecarga diante da enorme demanda social desatendida, sobretudo em circunstâncias de grave crise fiscal. Mas o ponto crucial consiste nas relações entre hobbesianismo e pretorianismo: em que medida caberá esperar que a deterioração hobbesiana termine por engendrar de novo o pretorianismo na forma mais convencional do protagonismo militar? É sem dúvida imaginável a situação em que o agravamento das condições de insegurança acabe resultando em que a população venha a ansiar diretamente pela afirmação de um poder ditatorial, o que, aliás, já é respaldado pelas disposições encontradas por muitas pesquisas entre amplas parcelas da opinião popular brasileira. Mas podemos defrontar-nos aqui com formas mais tortuosas e inéditas de se dar a articulação entre os dois fenômenos. É o que sugere, em especial, o exemplo atual da Venezuela de Hugo Chávez, em que uma história pessoal de golpismo militarista, ou a cara mais rombuda do pretorianismo, acaba se transformando em recurso valioso na obtenção de maciço apoio popular e viabilizando a experiência cesarista de óbvios riscos que lá presenciamos.

Cabe talvez fechar estas notas realçando brevemente certas feições que o problema da identidade adquire nesta esquina do ano 2000 e dos 500 anos da história brasileira. A indagação decisiva consiste em como se poderá fazer coexistir apropriadamente os aspectos sociopsicológicos, relativos à ligação entre identidade pessoal e identidade coletiva, e os aspectos objetivos relacionados à economia e à atuação econômico-social do Estado. O nacionalismo brasileiro "clássico", cuja elaboração intelectual se deveu sobretudo ao Instituto Superior de Estudos Brasileiros (ISEB), nos anos 50, pretendeu fundir esses dois aspectos. Contra as ingenuidades do patriotismo tradicional, a melhor maneira de afirmar a identidade coletiva consistiria em levar a cabo as tarefas materiais do desenvolvimento econômico e criar as condições para a autonomia nacional, de acordo com um modelo de "potência autônoma" claramente inspirado nos Estados Unidos. E o Estado teria, sem dúvida, importante papel a cumprir no empreendimento, em contraste com a curiosa esquizofrenia atual de certos setores de opinião que sustentam a um tempo a retórica do "Estado mínimo" e a da necessidade de "vontade política" para formular e executar um "projeto nacional", que remete a um Estado ativo e complexo.

Há, por certo, um sentido em que a referência ao Estado continua a impor-se como parte da inescapável referência ao nacional. $\mathrm{O}$ aparelho do Estado nacional segue sendo um instrumento indispensável e um objeto crucial de disputa pelos diversos interesses setoriais. Se os processos correntes 
o debilitam, tanto pior: será preciso enfrentar o desafio de capacitá-lo (concomitantemente com o desafio novo de criar seu equivalente funcional na escala transnacional em que se afirmam os mecanismos de mercado). Contudo, a fusão isebiana entre identidade e economia se torna claramente problemática, e os obstáculos opostos pela dinâmica transnacional da globalização a qualquer pretensão autárquica ou mesmo autonomista nos convidam a tratar de solucionar o problema da identidade coletiva e pessoal em termos que o dissociem das vicissitudes ligadas ao eventual processo de desenvolvimento material: por que não optar pela inserção tão apta e expedita quanto possível à dinâmica mercantil transnacional e tomar as questões de identidade no terreno cultural ao qual elas propriamente pertenceriam? Nessa óptica, quaisquer que sejam as imposições daquela inserção, a indagação seria apenas a de como preservar os valores associados a nossas características culturais próprias: o português do Brasil (cujo desaparecimento profetas supostamente competentes já prevêem) ou, mais folcloricamente, o samba de breque ou a modinha de viola, o futebol da malícia e da ginga de corpo...

Mas isso se liga de maneira complexa com o problema social. Nossa "questão nacional" se identifica fortemente com a "questão social" ou o problema da igualdade, e - sem falar de aspectos mais turvos, em que a folclorização de certos temas dissimula, por exemplo, a persistência de delicados problemas no plano das relações raciais e seu impacto sobre a identidade nacional - não se pode pretender defender os simpáticos valores culturais indicados ao custo da solução do problema social brasileiro: não se pode pretender preservar a favela para preservar o samba autêntico, e é certamente melhor ser um Canadá próspero e igualitário, mesmo se economicamente dependente e de identidade nacional meio descolorida, do que um Brasil de identidade nacional talvez marcante, mas desigual e injusto. Não obstante, diante das perversidades sociais das tendências espontâneas do processo mundial no plano econômico-tecnológico e da inviabilidade de um keynesianismo internacional no futuro visível, contar com efetiva ação social do Estado supõe a solidariedade nacional. E algum tipo de nacionalismo terá, sim, de saber afirmar-se, ainda que necessariamente imbuído de espírito crítico.

Fábio Wanderley Reisé professor da Universidade Federal de Minas Gerais (UFMG). 